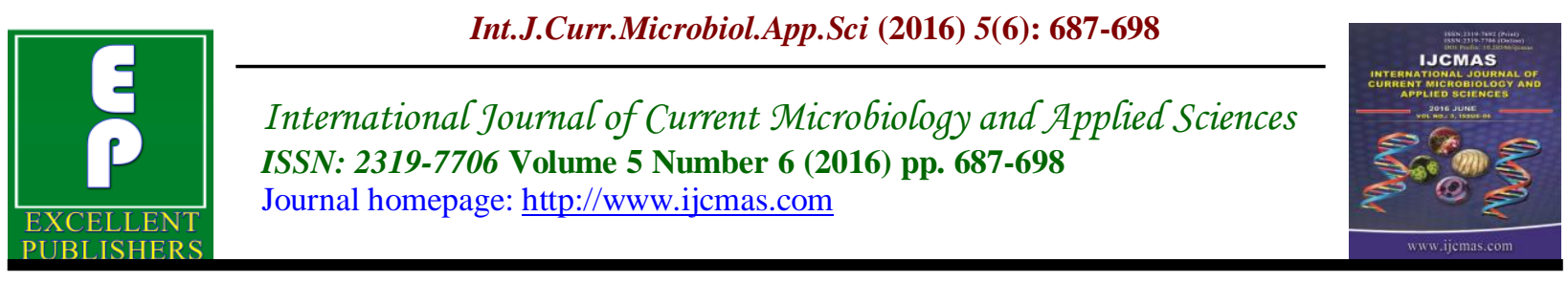

Original Research Article

http://dx.doi.org/10.20546/ijcmas.2016.506.075

\title{
Molecular Typing of Methicillin Resistant Staphylococcus aureus Colonizing Egyptian Healthcare Workers and Patients
}

\author{
Wafaa K.M. Mahdi*, Noha A. Hassuna, Mona A. Esmail, \\ Safaa S. Hammad and Sayed F. Abdelwahab
}

Microbiology and Immunology Department, Faculty of Medicine, Minia University, Minia 61511, Egypt

*Corresponding author

\begin{tabular}{|c|c|}
\hline & A B S T R A C T \\
\hline & \multirow{13}{*}{$\begin{array}{l}\text { Methicillin-resistant Staphylococcus aureus (MRSA) is a global public health } \\
\text { problem. MRSA infection leads to longer hospital stays, increased healthcare cost, } \\
\text { and significant morbidity and mortality. We determined the prevalence of MRSA at } \\
\text { the Intensive Care Units (ICU) of Minia University Hospital (MUH) and Minia } \\
\text { Insurance Hospital (MIH) among Egyptian healthcare workers (HCW) and } \\
\text { patients. Also, we examined the MRSA molecular types to determine if the HCW } \\
\text { contribute to the spread of MRSA infection. This study included } 260 \text { different } \\
\text { samples that included } 110 \text { nasal swabs from HCW, } 60 \text { swabs from endotracheal } \\
\text { tube secretion of patients and } 90 \text { swabs from the hospitals' environment (roofs, } \\
\text { floor, beds, walls, sheets and equipment). The swabs were cultured on mannitol salt } \\
\text { agar and MRSA strains were identified by biochemical reactions, antimicrobial } \\
\text { susceptibility testing and PCR using specific primers for the coagulase and mecA } \\
\text { gene. MRSA strains were confirmed by PCR through detection of mecA gene. } \\
\text { Typing of the coagulase-positive strains was performed using RFLP. MRSA } \\
\text { colonization was } 11.8 \% \text {, } 13.3 \% \text { and } 2.2 \% \text { among HCW, patients and } \\
\text { environmental samples, respectively. Antibiotyping revealed four different } \\
\text { antibiotypes. Antibiotype } 2 \text { was the most common pattern ( } 8 \text { isolates), } 6 \text { of them } \\
\text { belonged to the coA C2a genotype. Interestingly, RFLP of coA gene revealed } \\
\text { sharing of strains between HCW and patients. Our results sets a warning that } \\
\text { Egyptian HCW could be a possible source or transmission of MRSA infection, } \\
\text { which necessitates the application of proper infection control measures. }\end{array}$} \\
\hline & \\
\hline Healthcare- & \\
\hline & \\
\hline & \\
\hline MRSA; & \\
\hline & \\
\hline Article & \\
\hline & \\
\hline Available Online: & \\
\hline & \\
\hline & \\
\hline & \\
\hline
\end{tabular}

\section{Introduction}

Methicillin-resistant Staphylococcus aureus (MRSA) is a global public health problem, which causes significant morbidity and mortality. MRSA has been defined as Staphylococcus aureus isolates with oxacillin minimum inhibitory concentration (MIC) of $4 \mu \mathrm{g} / \mathrm{mL}$ or those containing the $m e c A$ gene. However, the presence of $m e c A$ gene does not always mean resistance to oxacillin and mecA-harboring isolates that are sensitive to oxacillin has been isolated in several parts of the world; reviewed in (Pournaras et al., 2015). MRSA infection leads to longer hospital stays and increased 
healthcare cost. MRSA is frequently recognized as a hospital-acquired organism. Variants capable of causing infections in the community are known as communityacquired MRSA (CA-MRSA) and represent an emerging and serious public-health issue as well. A study of a large surgical intensive care units' (ICU) cohort in USA over a 15 month period showed that $8 \%$ of patients were colonized with MRSA at the time of admission, and that these subjects can serve as a reservoir for the spread of this pathogen (Albrich, 2008). On the other hand, many patients who are not infected on admission may actually become colonized with MRSA. The possibility of MRSA acquisition and carriage by healthcare workers $(\mathrm{HCW})$ is a source of anxiety and concern among HCW and public health authorities. The prevalence of MRSA among HCW was $6.1 \%$ and $15.5 \%$ in the Middle East and Africa, respectively, reviewed elsewhere. Transmission to patients is then likely to occur during routine patient care. Air-borne transmission appears to be quantitatively related to the number of Staphylococcus aureus ( $S$. aureus) colonizing the anterior nares. Eradication of MRSA from $\mathrm{HCW}$ to limit transmission of MRSA in healthcare settings can be accomplished by topical or systemic antimicrobial agents.

The emergence of antibiotic resistance is considered one of the most important threats to human health in the $21^{\text {st }}$ century. ICU are particularly appropriate for the rapid emergence and spread of MRSA because of the wide variety of pressures; which include frequent use of broad spectrum antibiotics, crowding of patients with high levels of disease acuity in relatively small area. Resistance to most $\beta$-lactam antibiotics in Staphylococci is mediated by an altered penicillin-binding protein (PBP), which is encoded by mecA genes. There are limited data about the potential transmission of
MRSA in the healthcare settings in Egypt. To this end, we examined the patterns of colonization with MRSA among patients and HCW in the ICU, as well as the environment at two Minia Governorate Hospitals and tried to trace the source of infection.

\section{Subjects and Methods}

\section{Collection of Samples}

This study was carried out at the Microbiology and Immunology Department, Faculty of Medicine, Minia University in the period from April 2014 to November 2014. The study protocol was approved by the IRB and council of the Minia University Faculty of Medicine. A written informed consent was obtained from the study participants. Two-hundred sixty samples were collected from three sources as follows: hospital staff members, patients and environment. Samples were collected form Minia University Hospital (MUH) and Minia Insurance Hospital (MIH). Both hospitals are located in the same city and are $\sim 3 \mathrm{Km}$ apart where samples were collected from various ICU with bed capacities ranging from 8-10 beds with an admission rate of 1000-1500 cases per year. The samples included 110 nasal swabs from $\mathrm{HCW}$ (70 from MUH and 40 from $\mathrm{MIH}$ ), including physicians, nurses, house-keeping staff, and safety workers. All HCW who agreed to participate were enrolled into the study. Also, a total of 90 swabs were collected from the environment of both MUH and MIH (ceilings, floors, beds, walls, sheets and equipment). In addition, 60 swabs were collected from the endotracheal tube secretion from 60 patients (45 from MUH and 15 from $\mathrm{MIH}$ ) showing signs of pneumonia 48 hours or more following admission. Full history was taken from each HCW and patient, including; age, gender, 
and residence. Patients enrolled in our study were those exposed to respiratory tract infections acquired 48-72 $\mathrm{h}$ following admission into the hospitals (healthcareassociated infections).

\section{Isolation, Growth and Identification of Bacteria}

The swabs were transferred immediately in enrichment broth and were cultured aseptically on nutrient, blood and mannitol salt agar plates, at $37^{\circ} \mathrm{C}$ for $24 \mathrm{~h}$. Colonies were confirmed to be $S$. aureus both microscopically and biochemically (catalase, coagulase, $\beta$-hemolysis, and sugar fermentation).

\section{Antimicrobial Susceptibility Testing}

The following antimicrobial discs were used: Ampicillin $(10 \quad \mu \mathrm{g})$, Ampicillin/Sulbactam $(10 \mu \mathrm{g})$, Cephradine $(30 \mu \mathrm{g})$, Cefoxitin $(30 \mu \mathrm{g})$, Cefotaxime (30 $\mu \mathrm{g})$, Cefepime $(30 \mu \mathrm{g})$, Flucloxacillin $(5 \mu \mathrm{g})$ and Imipenem $(10 \mu \mathrm{g}$; all from Bioanalyse, Canada). Vancomycin $(30 \mu \mathrm{g})$ was purchased from Oxoid (England). Methicillin resistance was tested by using the Kirby-Bauer disc diffusion method(9) using oxacillin $(1 \mu \mathrm{g})$ disc on MuellerHinton agar (Oxoid, England) with $24 \mathrm{~h}$ incubation at $35.8^{\circ} \mathrm{C}$. The results were interpreted according to the guidelines of Clinical Laboratory Standards Institute.

\section{DNA Extraction and PCR amplification}

DNA was isolated by using Gene JET Genomic DNA Purification Kit (Thermo Scientific, USA)following the manufacturer's instructions. Primers specific for the mecA gene were used to amplify the methicillin resistance gene, which codes for PBP responsible for $\square$-lactam antibiotic resistance. The primer sequences used for the amplification of themecA gene were as follows: $\mathrm{F}$ 5'-TAGAAATGACTGAAC
GTCCG 3', mecAR: 5'GATGCCATTGTAACTAGCGTT-3'. The thermal cycler was programmed as follows: an initial denaturation step at $95^{\circ} \mathrm{C}$ for 5 min, followed by $1 \mathrm{~min}$ of denaturation at $95^{\circ} \mathrm{C}, 30 \mathrm{sec}$ of annealing at $47^{\circ} \mathrm{C}$ and $30 \mathrm{sec}$ of extension at $72^{\circ} \mathrm{C}$ for 30 cycles and a final extension step at $72^{\circ} \mathrm{C}$ for $5 \mathrm{~min}$. PCR products were resolved on $1 \%$ agarose gel with ethidium bromide dye and visualized under a UV trans-illuminator (BiometraGoettingen, Germany).

The presence and molecular type of the coagulase ( $c o A)$ gene was screened in $m e c A-$ positive strains using specific primers (8) $c o A$ F:5'-ATAGAGTGCTGGTACAG-3', coA R: 5'-GCCATTGTAACTAGCGTT-3'. Molecular typing of the obtained coagulase gene products was performed by RFLP after digestion with $A l u \mathrm{I}$ restriction enzyme (Fast Digest AluI, Thermo Scientific, USA)at the recognition site 5'AGCT, 3'TCGA and cutting occur at : 5'---AG CT---3' and 3'--TC GA---5 . RFLP was done as follows: 1 $\mu \mathrm{L}$ of Fast Digest enzyme, $10 \square$ Lof PCR products, $2 \mu \square \mathrm{L}$ of green buffer, and $17 \square \mathrm{L}$ of nuclease-free water were incubated at $37^{\circ}$ $\mathrm{C}$ for 15 minutes. The resulting RFLP fragments were visualized by electrophoresis on 3\% agarose gel using 50 bp ladder (QIAGEN Gelpilot), respectively.

\section{Statistical Analysis}

Statistical analyses were performed by the Statistical Package for Social Science (SPSS) version 11.0 (IBM, USA). Chisquare test and student's $t$ test were used where appropriate. $p$ values of $<0.05$ were considered significant.

\section{Results and Discussion}

\section{Bacterial Isolation and Identification}

Out of 260 samples, $50 \mathrm{~S}$. aureus isolates (19.2\%) were identified, which included 27 
isolates $(24.5 \%)$ from the $110 \mathrm{HCW}, 18$ isolates $(30 \%)$ from the 60 patient and 5 isolates $(5.6 \%)$ from the 90 environmental samples. According to culture, and biochemical characteristics and oxacillin resistance, MRSA was identified in 25 samples (9.6\%) out of the 260 samples. These 25 isolates represented a prevalence of $13.6 \%$ (15 isolates) among HCW, $13.3 \%$ (8 isolates) among patients and $2.2 \%$ (two isolates) in the environment, respectively. The mean age of the $110 \mathrm{HCW}$ was $29.2 \pm$ 4.5 years. The frequency of MRSA in HCW regarding gender, job, residence and hospital is shown in Table 1.

Regarding the job, the highest prevalence rates were found among the nursing staff where 29\% (20 from 67) were nasal carriers of $S$. aureus and $13(19.4 \%)$ were carrier of MRSA. Also, the number of $\mathrm{HCW}$ colonized with $S$. aureus at MUH was 23 $(32.9 \%)$ while those at $\mathrm{MIH}$ were $4(10 \%$, $p=0.007)$. On the other hand, the mean age of the 60 patients was $61.4 \pm 7.4$ years with 5 MRSA strains isolated from males $(15.2 \%)$ and 3 strains isolated from females $(11.2 \%, p>0.05)$.

\section{Antibiotic Susceptibility Testing and resistance profile of MRSA isolates}

All S. aureus isolates were subjected to antibiotic sensitivity testing using 10 antimicrobial agents $(\beta$-lactams and Vancomycin) as described in the Subjects and Methods section. MRSA were detected according to oxacillin resistance with inhibition zone $\leq 10 \mathrm{~mm}$. All of the MRSA isolates were resistant to all the penicillins tested and were all (100\%) susceptible to imipenem.Vancomycin resistance rate among the 25 MRSA isolates was $36 \%$. On the other hand, resistance rates toCefradine, Cefoxitin, cefepime and Cefotaxime were $100,100,48 \%$, and $75 \%$, respectively
(Table 2). A $100 \%$ susceptibility to imipenem and almost half of the isolates were recorded as susceptible to cefepime. As shown in Table 2, MRSA strains showed 4 antibiotypes or resistance profiles (4 different patterns of resistance to $\beta$-lactams and Vancomycin). The commonest antibiotype were antibiotype 1 (9 isolates) with resistance to all antibiotics except Imipenem and antibiotype 2 that showed resistance to all used antibiotics except Imipenem, Cefepime and Vancomycin.According to this antibiotyping there were shared strains between $\mathrm{HCW}$, patient and environment (Table 2).

\section{Detection of mecA Gene among MRSA isolates}

To test the mechanism of resistance of MRSA isolates in our study,mecA gene was detected by PCR as described in the Subjects and Methods section. An example of mecA PCR amplification among $S$. aureus isolates that were resistant to Methicillin is shown in Figure 1. An amplicon of 154 bp was considered indicative for the presence of mecA gene, which is responsible for Methicillin resistance among MRSA isolates. The PCR data indicated that $22(88 \%)$ of MRSA isolates were positive for the mecA gene. These included 13 isolates from $\mathrm{HCW}$ (86.7\%), 7 from patients $(87.5 \%)$ and all two environment isolates $(100 \%)$.

\section{PCR Detection of MRSA coagulase (coA) gene}

The PCR amplification of the coAgene was performed as described in the Subjects and Methods section. An example of $c o A$ PCR detection among MRSA isolates is shown in Figure 2. The data show that all MRSA isolates $(100 \%)$ were positive for the coA gene. Four different $c o A$ types were found 
based on polymorphisms in the size of the coagulase gene. These were $700 \pm 20 \mathrm{bp}$, $780 \pm 20 \mathrm{bp}, 980 \pm 20 \mathrm{bp}$, and $500 \pm 20 \mathrm{bp}$. The samples that were MRSA-positive were classified according to the coagulase gene product size. It was found that the $780 \pm 20$ bp type was the most abundant accounting for $86.5 \%$, while the $700 \pm 20,980 \pm 20$ and $500 \pm 20$ bp products accounted for the remaining $13.5 \%$ ( 1 isolate or $4.5 \%$ of each type).

Typing of coA gene by RFLP and relationship between antibiotypes and $\operatorname{coA}$ genotype

The different size coagulase gene products were subjected to RFLP analysis by restriction digestion using AluI restriction enzyme as described in Subjects and Methods section. The coAPCR products, also, yielded different restriction patterns on digestion with the AluI enzyme as shown in Figure 3. The relationship between antibiotype and coAgenotyping is shown in Table 3. As shown, a single C1 sample from one HCW showed pattern 1 antibiotype (resistant to all antimicrobial agents used except Imipenem). The $\mathrm{C} 2 \mathrm{~b}$ environmental sample and the C3 sample from patient showed pattern 2 antibiotype (resistant to all antimicrobial agents tested except Cefipime, Imipenem and Vancomycin). The C4 (from environment) showed pattern 3 antibiotype (resistance to all antimicrobial agents used except Cefipime, Cefotaxime, Imipenem and Vancomycin).

We found that the remaining 18 samples (from $\mathrm{HCW}$ and patient) had the $\mathrm{C} 2 \mathrm{a}$ coAgenotype and showed 4 different patterns of resistance. These were $6(33.3 \%)$ ofantibiotype 1, $6(33.3 \%)$ of antibiotype 2,2 (11.1\%) of antibiotype 3, and 4 (22.2\%) of antibiotype4. As mentioned previously, antibiotype 2 was the most common pattern (8 isolates), 6 of them belonged to the common $\operatorname{coA} \mathrm{C} 2$ a genotype. The data show that there were shared strains between HCW and patients suggesting that $\mathrm{HCW}$ could be the source of infection.

In this study, it was found that $27(24.5 \%)$ out of $110 \mathrm{HCW}$ serving the ICU patients were colonized by $S$. aureus of whom 13 $(11.8 \%)$ were positive for nasal carriage of MRSA, though they were asymptomatic. MRSA colonization and infection have increased dramatically over the past two decades, evidenced by the increasing number of reported outbreaks in the literature (Sydnor et al., 2011). A study in an Indian hospital reported that $1.8 \%$ of HCW had colonization with MRSA in the anterior nares(Mathanraj et al., 2009). The nasal carriage rate of $S$. aureus found in the present study $(24.5 \%)$ is similar to that reported in another study, where 34 (28.8\%) of the $118 \mathrm{HCW}$ had $S$. aureus and 15 $(12.7 \%)$ had MRSA, respectively.

A significantly higher colonization with $S$. aureus $(p=0.007)$ was noted at MUH (23 out of $70 \mathrm{HCW} ; 32.9 \%$ ) than MIH (4 out of $40 \mathrm{HCW} ; 10 \%)$. This was also true for colonization with MRSA $(17.1 \%$ vs. $7.5 \%$, respectively), which indicates an increased risk of developing MRSA infections at MUH. The higher frequency of MRSA among $\mathrm{HCW}$ and patients at MUH compared to $\mathrm{MIH}$ in addition to the presence of the only isolated two MRSA strains from the environment at $\mathrm{MUH}$, all point to the lack of proper infection control measures at MUH and draws the attention towards the strict implementation of appropriate measures at MIH. On the other hand, there was no significant difference in MRSA colonization between males and females. Regarding the job category, we found out that the highest prevalence rate of nasal 
carriage of $S$. aureuswas among the nursing staff (20 from 67; 29\%) and this was also true for MRSA carriage(13 out of 67; $19.4 \%)$. These data coincide with another study as the overall rate of MRSA nasal carriage among $\mathrm{HCW}$ was $8.9 \%$ (10/112)and the frequency was highest $(80 \%$ or $8 / 10$ ) among nurse. This may reflect the fact that nurses have a higher level of physical contact with patients compared with other categories of medical staff due to constant exposure to infected patients.

In our study, from 60 patients with nosocomial infection, $18(30 \%)$ had $S$. aureus infection and $8(13.3 \%)$ had MRSA infection. This means that $44 \%$ of $S$. aureus infections were caused by MRSA strains. These data are analogous to another study at Minia University that reported a prevalence of S. aureus of $29.2 \%$ among wound patients, of which $65 \%$ were MRSA. The MRSA isolates reported in this study were completely resistant to Ampicillin (100\%). The present study showed differential resistance rates against Cephalosporins; where the isolates were resistant to Cefradine, Cefoxitin, Cefotaxime and cefepimeat rates of $100,100,75 \%$, and $48 \%$, respectively (Table 2).On the other hand, $100 \%$ of the isolates were susceptible. MRSA is known to be resistant to most beta lactams except next generation molecules.In this regard and similar to our findings, other studies $(8,9,15,16), \quad$ reported high susceptibility to imipenem and partial susceptibility to cephalosporins. Another possible explanation for this susceptibility could be the non-extensive usage of imipenem or cefepime for treatment of MRSA in our hospitals leading to higher sensitivity. In addition, the fact that community-acquired MRSA could be introduced into the hospitals and that they are known to be sensitive to carbapenems, particularly imipenem, requires further investigation and tracing of the isolated strains. Only one study was conducted previously in our region and showed similar susceptibility of MRSA to the used cephalosporins( Ahmed, 2014). In regard to Cefotaxime, $75 \%$ resistance rate was demonstrated in our study, which is higher than that of another report in which resistance to Cefotaxime was $17 \%$. In our study resistance to Vancomycin was $36 \%$, which was much higher than a previous study in the same locality among surgical site infected patients, which was $1.5 \%$. This marked rise in the vancomycin resistance could be due to the marked abuse of vancomycin in clinical practice as a drug of choice for MRSA. The isolation of MRSA from ICU in this study; where various risk factors e.g. long hospital stay and the use of broad-spectrum antimicrobials; could help in the emergence of vancomycin resistant MRSA (VRSA).

Methicillin resistance in Staphylococci is mediated by the mecA gene which encodes for the PBP2A resulting in reduced affinity for the $\beta$-lactam antibiotics including the Penicillinase-resistant penicillins. In this study, PCR was used to detect mecAgene in the 25 MRSA isolates. Twenty two isolates $(88 \%)$ were positive for mecA gene, whereas three isolates $(12 \%)$ were negative. Of the three isolates, two were resistant to Oxacillin at the borderline of the inhibition zone and were thus termed "moderately resistant $S$. aureus (MODSA). This finding agreed with the published data (Al-Ruaily et al., 2011) that showed that out of 15 MRSA isolates, 13 MRSA isolates expressed the $m e c A$ gene by PCR typing in addition to $\square$ lactamase enzyme production. Regarding the presence of mecA gene among the resistant isolates, a report showed that 32 MRSA isolates were initially identified by disk diffusion method, then the PCR confirmed that only 30 isolates (93.8\%) 
were positive for the presence of mecA gene(Araj, 1999). The three isolates that were negative for $m e c A$ gene could have other resistance mechanism(s) e.g., reduced drug accumulation or altered target site. Another possibility is that we could not detect the mecA gene by the used methodology.

Table.1 Frequency of MRSA in HCW regarding gender, residence and job

\begin{tabular}{|l|l|l|}
\hline HCW group $(\mathbf{n = 1 1 0})$ & No $(\%)$ & $P$ value \\
\hline $\begin{array}{l}\text { Gender: } \\
\text { Male }(\mathrm{n}=49) \\
\text { Female }(\mathrm{n}=61)\end{array}$ & $\begin{array}{l}6(12.2 \%) \\
9(14.8 \%)\end{array}$ & 0.703 \\
\hline Residence: & $9(15.3 \%)$ & \\
Rural $(\mathrm{n}=59)$ & $6(11.8 \%)$ & 0.595 \\
Urban $(\mathrm{n}=51)$ & $2(6.7 \%)$ & \\
\hline Job: & $13(19.4 \%)$ & 0.094 \\
Physician $(\mathrm{n}=30)$ & $0(0 \%)$ & \\
Nurse $(\mathrm{n}=67)$ & & \\
Worker $(\mathrm{n}=13)$ & & \\
\hline
\end{tabular}

Table. 2 Resistance profile of MRSA isolates. The antimicrobial resistance of the isolates to 10 beta-lactam antibiotics was determined as described in the Subjects and Methods section. Isolates with similar resistance profile were grouped together. $\mathrm{R}=$ resistant, $\mathrm{S}=$ sensitive.

\begin{tabular}{|c|c|c|c|c|c|c|c|c|c|c|c|c|}
\hline Antibiotype & 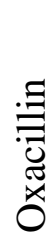 & 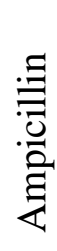 & 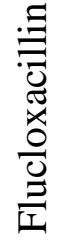 & 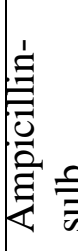 & Ũ. & Ũ. & 造 & 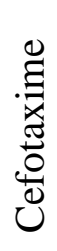 & 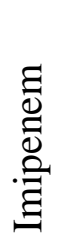 & 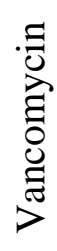 & Source of isolates & $\begin{array}{l}\text { No of } \\
\text { isolates } \\
\mathrm{N}=\mathbf{2 5} \\
(\mathbf{1 0 0 \%})\end{array}$ \\
\hline Antibiotype 1 & $\mathrm{R}$ & $\mathrm{R}$ & $\mathrm{R}$ & $\mathrm{R}$ & $\mathrm{R}$ & $\mathrm{R}$ & $\mathrm{R}$ & $\mathrm{R}$ & S & $\mathrm{R}$ & Patient and HCW & $9(36 \%)$ \\
\hline Antibiotype 2 & $\mathrm{R}$ & $\mathrm{R}$ & $\mathrm{R}$ & $\mathrm{R}$ & $\mathrm{R}$ & $\mathrm{R}$ & $\mathrm{S}$ & $\mathrm{R}$ & S & $\mathrm{S}$ & $\begin{array}{l}\text { Patients, HCW and } \\
\text { Env }\end{array}$ & $8(32 \%)$ \\
\hline Antibiotype3 & $\mathrm{R}$ & $\mathrm{R}$ & $\mathrm{R}$ & $\mathrm{R}$ & $\mathrm{R}$ & $\mathrm{R}$ & $\mathrm{S}$ & S & $\mathrm{S}$ & S & $\begin{array}{l}\text { Patients, HCW and } \\
\text { Env }\end{array}$ & $5(20 \%)$ \\
\hline Antibiotype4 & $\mathrm{R}$ & $\mathrm{R}$ & $\mathrm{R}$ & $\mathrm{R}$ & $\mathrm{R}$ & $\mathrm{R}$ & $\mathrm{R}$ & $\mathrm{R}$ & S & $S$ & Patient and HCWs & $3(12 \%)$ \\
\hline
\end{tabular}


Fig.1 Detection of MRSA mecA gene by PCR among the S. aureus isolates. The gene was amplified as described in the Subjects and Methods section. The lanes shown from left to right are arranged as follows:

L: 100 bp ladder; lane 1 negative control, lane 2 positive control, lane 3, 4, 6 and 7 are mecA positive (band at $154 \mathrm{bp}$ ) samples while lanes 5, 8, and 9 are negative samples.

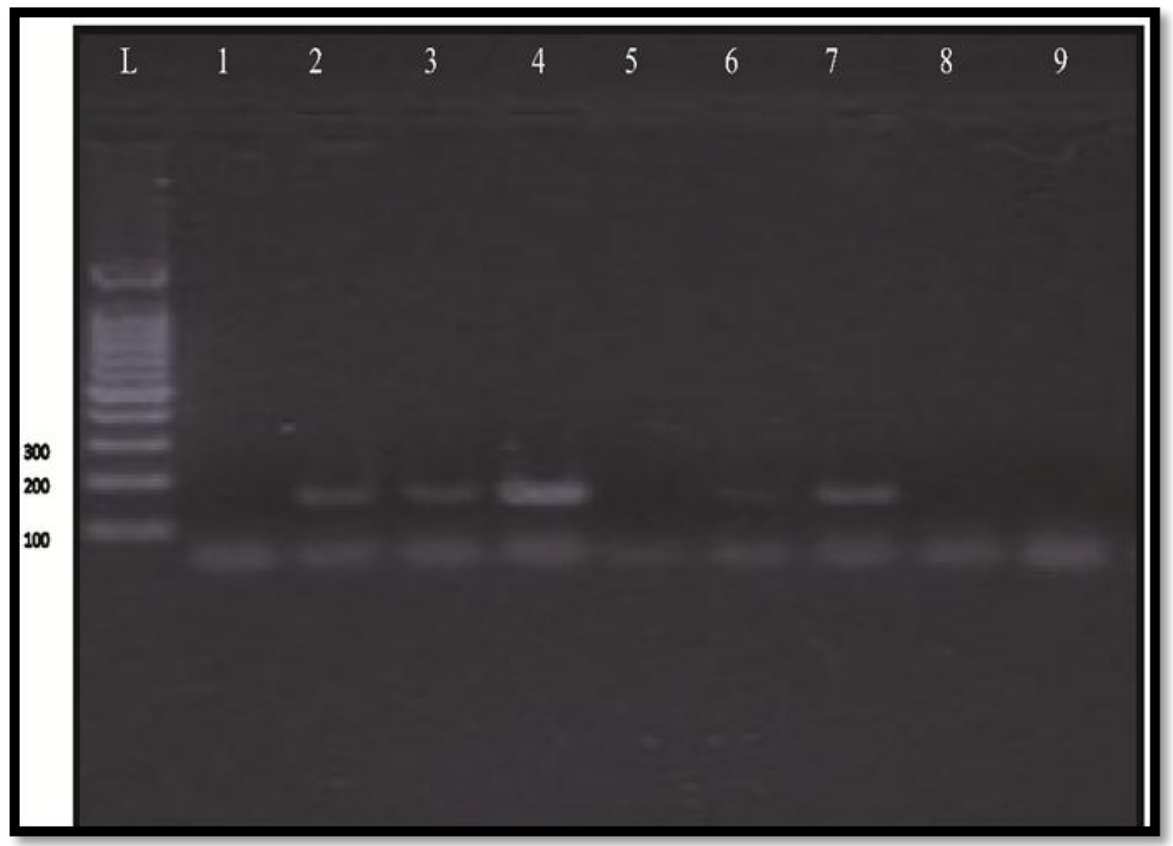

Fig.2 Detection of amplification products of MRSA coA gene by PCR. The PCR amplification of the coA gene was performed as described in the Subjects and Methods section. The lanes (from left to right) after the molecular size marker M: (100 bp ladder) show 4 different PCR product sizes as follows: lane 1:

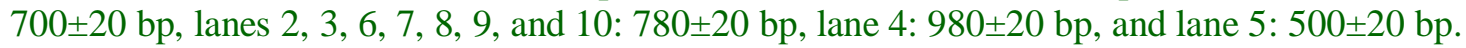

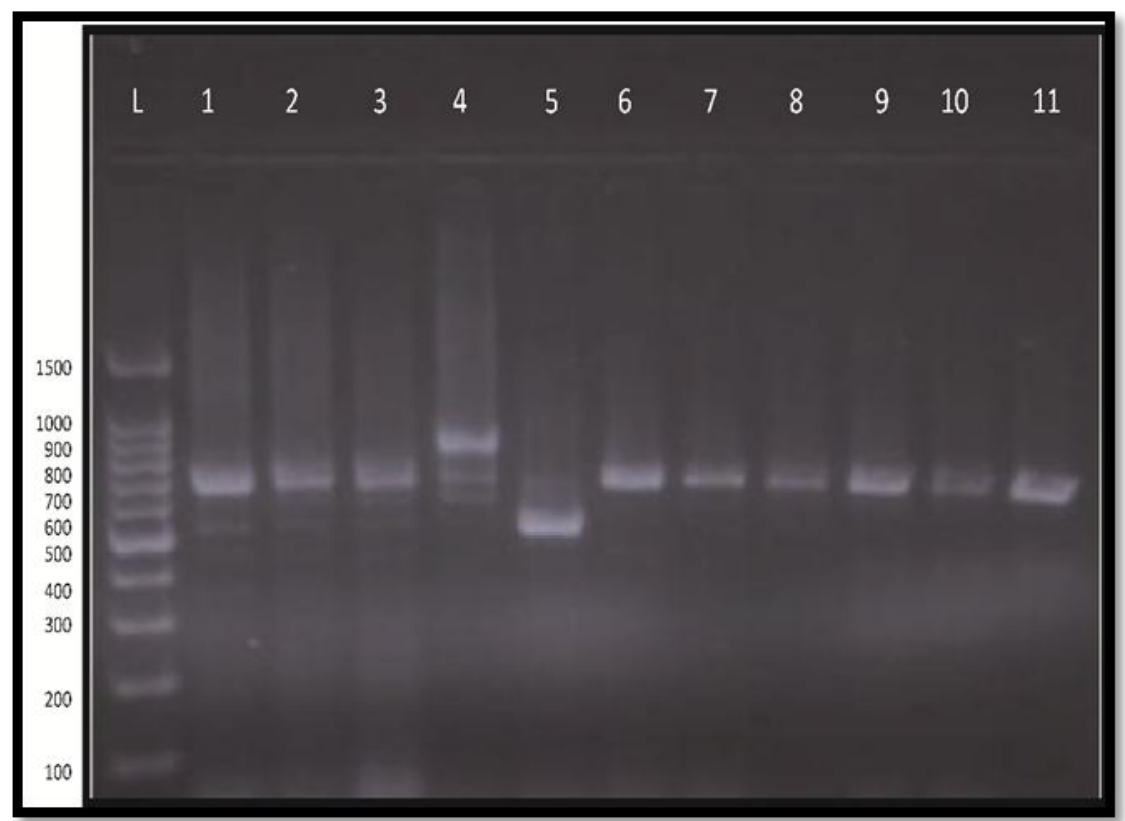


Fig.3 The coA PCR products yielded different restriction patterns on digestion with the enzyme AluI. The different size coagulase gene products were subjected to RFLP analysis by restriction digestion using AluI restriction enzyme as described in Subjects and Methods section. L: 50bp ladder, Lane1 shows coA C1 pattern, Lanes 2, 5, 8, 9, 10, and 11 show C2a pattern, Lane 4, and 7 show C4 pattern, Lane 3 shows C3 pattern while Lane 6 shows C2b pattern.

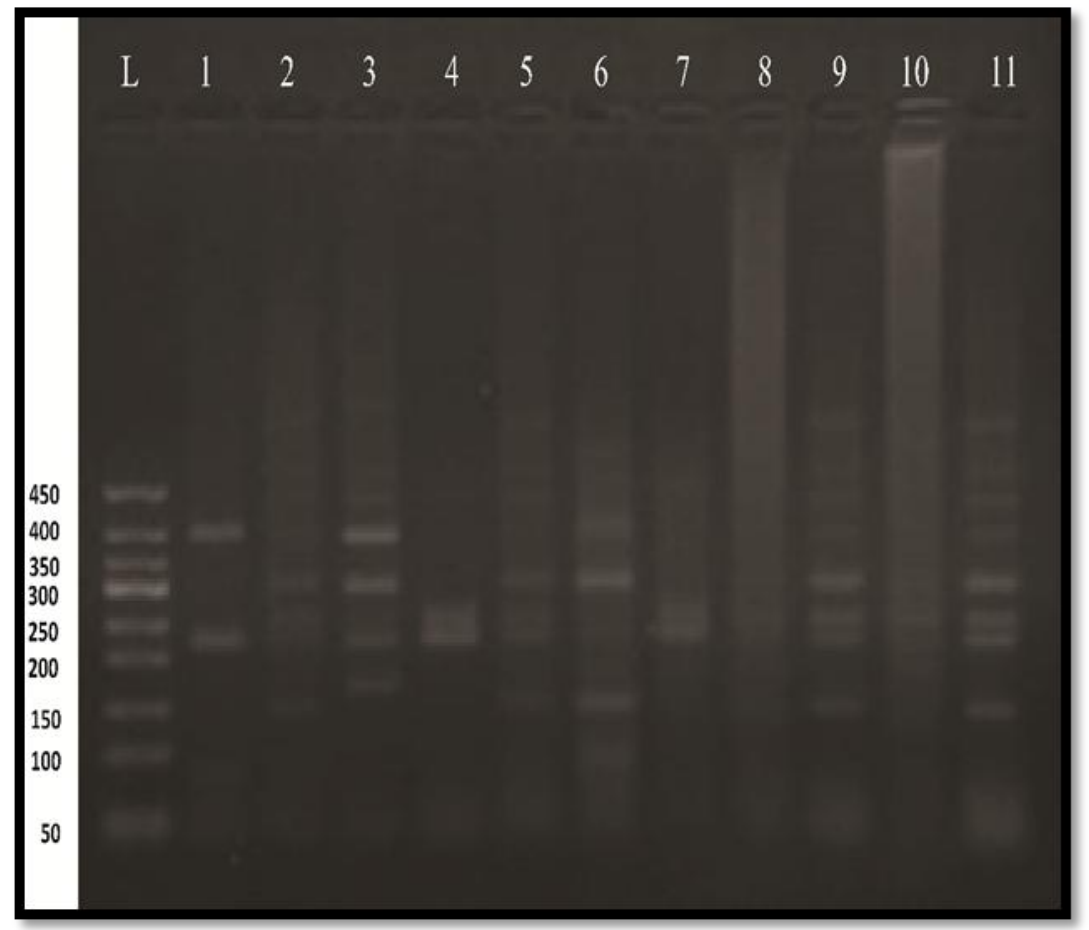

Table.3 Relationship between antibiotype and coA genotype of MRSA isolates

\begin{tabular}{|l|l|l|l|l|l|}
\hline $\begin{array}{l}\text { Anti-biotype/ } \\
\text { Genotypes }\end{array}$ & $\begin{array}{l}\text { Pattern 1 } \\
(\mathbf{n = 7})\end{array}$ & $\begin{array}{l}\text { Pattern 2 } \\
(\mathbf{n = 8})\end{array}$ & $\begin{array}{l}\text { Pattern 3 } \\
(\mathbf{n = 3})\end{array}$ & $\begin{array}{l}\text { Pattern } \\
(\mathbf{n = 4})\end{array}$ & $\boldsymbol{p}$ value \\
\hline C1 & $1(14.3 \%)$ & $0(0 \%)$ & $0(0 \%)$ & $0(0 \%)$ & \\
C2a & $6(33.3 \%)$ & $6(33.3 \%)$ & $2(11.1 \%)$ & $4(22.2 \%)$ & \\
C2b & $0(0 \%)$ & $1(12.5 \%)$ & $0(0 \%)$ & $0(0 \%)$ & 0.589 \\
C3 & $0(0 \%)$ & $1(12.5 \%)$ & $0(0 \%)$ & $0(0 \%)$ & \\
C4 & $0(0 \%)$ & $0(0 \%)$ & $1(33.3 \%)$ & $0(0 \%)$ & \\
\hline
\end{tabular}

Five different sized PCR products for the coagulase gene were detected in this study, and RFLP characterization showed that at least five coAtypes of MRSA strains were detected in our study. Of the MRSA-positive samples, we found that the $780 \pm 20 \mathrm{bp}$ product was most frequent. This could possibly be an indication of the extent of the spread of this particular MRSA clonal type. Another study in Saudi Arabia found that out of 73 MRSA-positive samples, the 570 bp product was the most frequent. We found that the 18 samples with the $\mathrm{C} 2 \mathrm{a} \operatorname{coA}$ genotype (from HCW and patient) show 4 different patterns of resistance to antibiotics. Among these 18 isolates, it was found that 
antibiotype 2 was the most common pattern ( 8 isolates), 6 of them belong to the common genotype $\mathrm{C} 2 \mathrm{a}$ pattern. These findings agreed with that of another report carried on 129 MRSA isolates from 17 different hospitals in various regions of Thailand, in which antimicrobial susceptibility testing with a panel of 10 antimicrobial agents showed 9 different antibiotypes. The antibiotypes 1 and 2 were the most common phenotypes with $44.2 \%$ and $35.6 \%$ of the isolates, respectively. Coagulase gene typing of MRSA strains showed 4 different genotypes. Coagulase gene PCR-RFLPs exhibited 4 patterns: A, B, C and D, with AluI digested PCR product fragments at $220 \pm 20$ and $220 \pm 20$ bp (pattern A); 400 \pm 20 and $220 \pm 20$ bp (pattern B); 420 \pm 20 and 220 20 bp (pattern C); and $510 \pm 20$ and $220 \pm 20$ bp (pattern D)( Janwithayanuchit et al., 2006). The percentages for each pattern were compatible with those from the coagulase gene typing method. The results indicated that antibiotypes 1 and 2 coagulase gene type III and PCR-RFLP pattern $\mathrm{C}$ were the epidemic strains, while the rest were sporadic strains. In the current study, there were $82 \%$ shared strain $(\mathrm{C} 2 \mathrm{a})$ between $\mathrm{HCW}$ and patient suggesting a common source of infection.

In conclusion, our results set a warning that HCW could be a possible source for transmission of MRSA infection, which necessitates the application of proper infection control measures.

\section{Acknowledgement}

This study was supported by personal funds and funds from Minia University.Minia University provided the laboratories, equipment andsome chemicals for the conduct of the study. Minia University has no role in study design; inthe collection, analysis and interpretation of data; in the writing of the report; and in the decision to submit the article for publication.

\section{Author Disclosure Statement}

ALL authors declare that "No competing financial interests exist"

Conflict of Interest: none declared.

\section{Authors contributions}

WKMM, NAH, SSH, MAE, and SFA conceived and designed the study. SSH, WKMM, NAH and SFA carried out the experiments and collected the data. WKMM, SSH, MAE, and NAH analyzed and interpreted the data. WKMM, and SFA wrote the manuscript. NAH, and MAE critically revised the manuscript.

\section{List of abbreviations}

community-acquired MRSA, CA-MRSA; healthcare workers, HCW; Intensive Care Units, ICU; Methicillin-resistant Staphylococcus aureus, MRSA; Minia Insurance Hospital, MIH;Minia University Hospital, MUH; moderately resistant $S$. aureus, MODSA; penicillin-binding protein, PBP; Staphylococcus aureus, S. aureus

\section{References}

Pournaras, S., Sabat, A.J., Grundmann, H., Hendrix, R., Tsakris, A., Friedrich, A.W. 2015. Driving Forces of Mechanisms Regulating OxacillinResistance Phenotypes of MRSA: Truly Oxacillin-Susceptible mecAPositive Staphylococcus aureus Clinical Isolates also Exist. Cur. Pharmaceut. Design, 21(16): 20482053.

Ippolito, G., Leone, S,. Lauria, F.N., Nicastri, E., Wenzel, R.P. 2010 Methicillin-resistant Staphylococcus 
aureus: the superbug. Int. J. Infect. Dis., 14(4): 7-11.

Mulligan, M.E., Murray-Leisure, K.A., Ribner, B.S., Standiford, H.C., John, J.F., Korvick, J.A., et al. 1993. Methicillin-resistant Staphylococcus aureus: a consensus review of the microbiology, pathogenesis, and epidemiology with implications for prevention and management. Amm. J. Med., 94(3): 313-328.

Albrich, W.C., Harbarth, S. 2008. Healthcare workers: source, vector, or victim of MRSA? The Lancet Infecti. Dis., 8(5): 289-301.

Bonten, M.J., Austin, D.J., Lipsitch, M. 2001. Understanding the spread of antibiotic resistant pathogens in hospitals: mathematical models as tools for control. Clinical infectious diseases. The Infect. Dis. Soc. Amm., 33(10): 1739-1746.

Kollef, M.H., Fraser, V.J. 2001. Antibiotic resistance in the intensive care unit. Annals Internal Med., 134(4): 298314.

Cespedes, C., Miller, M., Quagliarello, B., Vavagiakis, P., Klein, R.S., Lowy, F.D. 2002. Differences between Staphylococcus aureus isolates from medical and nonmedical hospital personnel. J. Clin. Micrbiol., 40(7): 2594-2597.

Dormanesh, B., Siroosbakhat, S., Khodaverdi Darian, E,. Afsharkhas, L. $2015 . \quad$ Methicillin-Resistant Staphylococcus aureus Isolated From Various Types of Hospital Infections in Pediatrics: Panton-Valentine Leukocidin, Staphylococcal Chromosomal Cassette mec SCCmec Phenotypes and Antibiotic Resistance Properties. Jundishapur J. Microbiol., 8(11): 113-141.

Yamazaki, H., Koyama, N., Omura, S,. Tomoda, H. 2008. Structure-activity relationships of stemphones, potentiators of imipenem activity against methicillin-resistant Staphylococcus aureus. J. Antibiot., 61(7): 426-441.

Patel, J., Cockerill, F., Alder, J., Bradford, P., Eliopoulos, G., Hardy, D. 2014. Performance standards for antimicrobial susceptibility testing; twenty-fourth informational supplement. Clin. \& Lab. Standards Inst. Antimicrob. Susceptib. Testing, 34(1): 1-230.

Sydnor, E.R., Perl, T.M. 2011. Hospital epidemiology and infection control in acute-care settings. Clin. Microb. Rev., 24(1): 141-173.

Mathanraj, S., Sujatha, S., Sivasangeetha, K., Parija, S.C. 2009. Screening for methicillin-resistant Staphylococcus aureus carriers among patients and health care workers of a tertiary care hospital in south India. Ind. J. Med. Microbiol., 27(1): 62-64.

Shibabaw, A., Abebe, T., Mihret, A. 2014. Antimicrobial susceptibility pattern of nasal Staphylococcus aureus among Dessie Referral Hospital health care workers, Dessie, Northeast Ethiopia. Int. J. Inf. Dis., 25: 22-25.

Kelly, V., Dillon, A.L., Carroll, A.M, McNamara, E.B. 2012. The prevalence of nasal carriage of meticillin resistant Staphylococcus aureus among healthcare workers in a non-acute healthcare facility. J. Infect. Preven., 13(4): 109-113.

Ahmed, E.F., Gad, G.F., Abdalla, A.M., Hasaneen, A.M., Abdelwahab, S.F. 2014. Prevalence of methicillin resistant Staphylococcus aureus among Egyptian patients after surgical interventions. Sur. Infect., 15(4): 404411.

Iyamba, J.M., Wambale, J.M., Lukukula, C.M., za Balega Takaisi-Kikuni, N. 
2014. High prevalence of methicillin resistant Staphylococci strains isolated from surgical site infections in Kinshasa. The Pan Afr. Med. J., 18: 322-330.

Al-Ruaily, M.A., Khalil, O.M. 2011. Detection of (mecA)gene in methicillin resistant Staphylococcus aureus (MRSA) at Prince A / Rhman Sidery Hospital, Al-Jouf, Saudi Arab. J. Med. Gen. \& Genom., 3(3): 41-45.
Maasad, M.J. 1999. Discrepancies between mecA PCR and conventional tests used for detection of methicillin resistant Staphylococcus aureus. Int. J. Antimicr. Agents, 11(1): 47-52.

Janwithayanuchit, I., Ngam-ululert, S., Paungmoung, P., Rangsipanuratn, W. 2006. Epidemiologic Study of methicillin-resistant Staphylococcus aureus by Coagulase Gene Polymorphism. Sci. Asia, 32: 127-132.

Araj, G.F., Talhouk, R.S., Simaan, C.J.,

\section{How to cite this article:}

Wafaa K.M. Mahdi, Noha A. Hassuna, Mona A. Esmail, Safaa S. Hammad and Sayed F. Abdelwahab. 2016. Molecular Typing of Methicillin Resistant Staphylococcus aureus Colonizing Egyptian Healthcare Workers and Patients. Int.J.Curr.Microbiol.App.Sci. 5(6): 687698. doi: http://dx.doi.org/10.20546/ijcmas.2016.506.075 